\title{
El Diablo Negro: Un Nuevo Pacto de Energía en México
}

\author{
Luis Alberto Luna Gómez* \\ José Javier de la Rosa Rodríguez** \\ María Antonieta Andrade Vallejo***
}

\section{RESUMEN}

La Reforma Energética aprobada al final de 2013 es parte de la política de posicionamiento global del Estado para atraer inversiones de capital nacional y extranjero, siendo, no sólo promotor, sino también socio. Esa acción determina la producción del territorio en diferentes escalas, aquí se muestran las escalas nacional, local y regional. La renta de la tierra se refiere, en este análisis a la producción de Petróleos Mexicanos (Pemex), mismo antes de 2013, cuando la Constitución Mexicana fue alterada en sus artículos 25, 27 y 28, acerca de la titularidad de los recursos, denominando tal acción de Reforma Energética. La empresa nacional Petróleos Mexicanos (Pemex) destinaba una renta por el uso dado al territorio nacional, capturada por la Secretaria de Hacienda y Crédito Público (SHCP), variando entre 35\% y 40\%, que representan una fuerte cantidad para inversión en gasto social e infraestructura para el país.

Palabras clave: Reformas; Petróleos Mexicanos (Pemex); Diablo negro.

\footnotetext{
* Doctor en Geografía. Profesor del Departamento de Ciencias Sociales de la Universidad Autónoma Metropolitana, Unidad Cuajimalpa. E-mail: luna@correo.cua.uam.mx

* * Profesor del Departamento de Procesos Sociales de la Universidad Autónoma MetropolitanaLerma. E-mail: jelarosa@yahoo.com

*** Profesora del Instituto Politécnico Nacional. ESCA. Santo Tomás. E-mail:mandradev@ipn.mx.
} 


\section{RESUMO}

\section{O DIABO NEGRO: UM NOVO PACTO ENERGÉTICO NO MÉXICO}

A reforma de energia aprovada no final de 2013 faz parte da política de posicionamento global do Estado para atrair investimentos de capital nacional e estrangeiro, sendo não só o promotor, também parcero. Esta ação determina a produção do território em diferentes escalas, nacional, local e regional são mostradas. A renda da terra está em causa, nesta análise à produção de Petroleos Mexicanos (Pemex), mesmo antes de 2013, quando a Constituição Mexicana foi alterada nos artigos 25, 27 e 28, sobre a propriedade dos recursos, denominando tal ação da Reforma Energética. A companhia nacional de petróleo Petroleos Mexicanos (Pemex) renda destinada para o uso dado território nacional, capturado pelo Secretaría de Hacienda y Crédito Público (SHCP), variando entre $35 \%$ e $40 \%$, o que representa uma boa quantidade de investimentos em gastos sociais e infra-estrutura para o país.

Palavras-chaves: Reformas; Petróleos Mexicanos (Pemex); Demônio negro.

\section{ABSTRACT}

\section{THE BLACK DEVIL: A NEW ENERGY PACT IN MEXICO}

The Energy Reform approved at the end of 2013 is part of the State's global positioning policy to attract domestic and foreign capital investments, being, not only promoter, but also partner. This action determines the production of the territory in different scales, here the national, local and regional scales are shown. Land rent refers, in this analysis, to the production of PetróleosMexicanos (Pemex), same before 2013, when the Mexican Constitution was altered in articles 25, 27 and 28, regarding the ownership of resources, denominating such action of Energy Reform. The national company Petróleos Mexicanos (Pemex) allocated an income for the use given to the national territory, captured by the Ministry of Finance and Public Credit (SHCP), varying between $35 \%$ and $40 \%$, which represent a large amount for investment in social spending and infrastructure for the country.

Keywords: Reforms; Petróleos Mexicanos (Pemex); Black devil. 


\section{Método por escalas geográficas}

La industria del petróleo es estratégica para el desarrollo del país y cómo señala Harvey en la acumulación por desposesión todo tiene que ver con el petróleo. Por tanto, anclada en la región Atitalaquia-Tula, Hidalgo, México, la refinería Miguel Hidalgo y el proyecto de la refinería Bicentenario hacen parte de ese sector económico clave.

Por un lado, el proyecto de la refinería Bicentenario se anunció en 2008, después de la crisis global, como acto semi-ilusorio, que tuvo algunos soportes materiales e institucionales, más no fue realizado, probando ser un gran acto de especulación por desposesión (MONREAL, 2014; LUNA, 2016D; HARVEY, 2003). Además de eso, la propuesta sirvió para apoyar la reforma de energía lanzada en 2013.

El discurso político, como discurso de interés económico, argumentó que Pemex estaba dejando de cumplir sus objetivos: producción, en términos de promover el desenvolvimiento, la industrialización, la capitalización nacional, el abastecimiento de energía barata para la economía y contribuir a la salud de las finanzas públicas, pretendiendo justificar la reforma de energía.

La concepción del Estado sobre la propiedad de territorio está basada en definirlo como un activo financiero puro. Todas las otras formas de propiedad de la tierra deben ser anuladas. "El espacio es un atributo material a todos los valores de uso” (HARVEY, 1990, p. 377; SACHER, 2015; INCLÁN, ET AL. 2012).

La renta es el concepto por el cual la economía política, enfrenta, tradicionalmente, el problema de la producción del espacio. La renta fortalece una base para varias formas de control social sobre la producción espacial y el desenvolvimiento del capitalismo. Eso es porque la tierra sirve, no sólo apenas como un medio de producción, más también como reserva de valor. El espacio es el componente necesario en toda la producción y actividad humana (HARVEY, 1990; LEFEBVRE, 1991; 2006; LUNA, 2017A; 2017C).

El crecimiento de los intercambios de mercancías, el incremento de las relaciones monetarias, el crecimiento del sistema de crédito, forman condiciones favorables para que se trate la "tierra cada vez más como un activo financiero" (HARVEY, 1990:351). Estos mismos factores, acrecientan nuestro desconocimiento espacial, considerando la geografía como una ciencia redundante y neutra (LUNA, DE LA ROSA Y RAMÍREZ, 2017; LACOSTE, 1977). 
El derecho sobre la tierra se torna una forma de capital ficticio. "El elemento especulativo está siempre presente en el comercio de tierras" (Harvey, 1990, p. 370). La especulación en tierra puede ser necesaria para el capitalismo, más las orgias especulativas se tornan una fuente de destrucción para el propio capital (HARVEY, 1990:372).

Así, analizando el desarrollo del proyecto de la refinería Bicentenario, se entiende como se adecuaron la especulación y la deuda pública a la política de posicionamiento y no a la capacidad productiva de la compañía Petróleos Mexicanos, para reinversión de los beneficios y su distribución social. Las acciones sobre los territorios formulados por el Estado tuvieron como uno de los objetivos alterar los artículos de la propiedad territorial (Art. 25, 27 e 28 de la Constitución), a fin de atraer y retener las inversiones de capital privado nacional e internacional dentro de las fronteras nacionales (LUNA, 2014; 2016A; 2017C).

\section{El diablo negro mexicano}

En cuanto a la producción de petróleo, el diablo negro, los yacimientos en Cantarell, en la Península de Yucatán, sustentaron la producción durante varios años. La crisis colocaba una pauta política de recomposición de las reservas y los trabajos de exploración, la reutilización de campos antiguos y el desarrollo de nuevos.

El rápido decline de los yacimientos en Cantarell, paso de más 2,000,000 de barriles a 500,000 barriles, en 2012. No han sido identificados otros campos tan grandes para explorar. La intensificación del trabajo de recuperación e identificación de nuevos yacimientos tiene como objetivo inmediato compensar el agotamiento de Cantarell para sustentar el volumen de producción. Así aconteció con el principal yacimiento de Ku-Maloob-Zaap; de ahí el desarrollo de Chicontepec y, más tarde, la exploración de campos en aguas profundas. En cuanto eso, la extracción total de petróleo bruto tendió a estancar y, en seguida, disminuyó ligeramente en los últimos años. Desde 2002, la producción se estancó en torno a los 3,200,000 de barriles por día, a ser reducidos para los 200,000 barriles en 2007 (IBARRA, 2013; LUNA 2014).

La procuración incesante del petróleo pasa por la estructura axiomática que define la cosificación. La racionalidad del mercado sucumbió a su irracionalidad autoinducida y de las mercadurías, el petróleo gana vida con sentido humano (TAUSSIG, 1993; 2015). El giro está en que anteriormente se 
consideraba al ser humano como cosa y hoy las cosas tienen personificación y representación humana (LUNA, DE LA ROSA Y RODRÍGUEZ, 2017).

Las formas sociales, economía y política, tienden a reducir o los hombres a números, más también transforman los recursos naturales, como el petróleo en demonios y dioses. La vida torcida, casquivana, con toda certeza, emerge de las cosas, transformando los productos sociales en seres animados, el petróleo en México es ese terrible diablo negro, el "Dios de los señores de la tierra”, un ser animado del que se dice devora a los hombres productores que dan vida (TAUSSIG, 1993).

El pensamiento dialéctico latinoamericano percibe, refleja, piensa y sabe que la Madre Tierra todavía está de parte de los trabajadores y campesinos, ella lucha con ellos para preservar la vida nueva dentro del viejo sistema metafísico de dualidades dialécticas, donde el bien también implica mal. El temor de que los grupos sociales tienen al diablo, así como el contexto simbólico que éste ocupa, refiere la persistencia latinoamericana de la creencia, según la cual los seres humanos y la naturaleza son una sola cosa. A fin de preservar la fertilidad, productividad, ningún elemento, por sí sólo, como el dinero se transforma en capital, puede dar lucro a costa del resto, principalmente la relación de despojo del plusvalor, transformando la totalidad en un medio para algo diferente de sí mismo (TAUSSIG, 1993; 2015).

La religión de los oprimidos puede atemperar el despojo y desposesión, y hacer que la gente se adapte, al mismo tiempo, puede provocar resistencia. El significado social de fetiche capitalista no esconde las relaciones económicas en su papel de relaciones entre cosas en sí mismas. La realidad económica, la desigualdad y la inmensa diferencia de modos de vida, nunca llegan a enmascarar las realidades humanas. Los ritos de la figura del Diablo y de la Santa Muerte que se hacen en México y América Latina manifiestan el choque dialéctico. Son los jóvenes y trabajadores que están en la vanguardia de la lucha de clases (TAUSSIG, 1996).

\section{Las mudanzas constitucionales}

La crisis financiera de Pemex impidió aumentar la capacidad de refinación y de equilibrar las líneas internas de producción. Al final del año 2007, la importación de productos petrolíferos llegó a casi 500,000 barriles de gasolina y ultrapasó los 300.000 barriles por día. El valor total de ese cambio 
sumara más de US \$14,000.000.000 de dólares, dejando un déficit líquido de casi US \$11,000.000.000 de dólares (ROUSSEAU, 2012; GONZÁLEZ, 2013; IBARRA, 2013). Sólo la importación de gasolina se elevó cerca de $40 \%$ del consumo nacional (IBARRA, 2013).

En términos de compras externas de petróleo que también se están expandiendo, requieren una inversión urgente en ductos, transporte y otros tipos de almacenamiento. La verdad, terminales marítimas deben modernizarse con quince o diez centros de almacenamiento, incluyendo las principales instalaciones (GONZÁLEZ, 2013; 2014).

La capacidad de refinación es de 1,500,000 barriles diarios, de los cuales apenas 39\% son aceites pesados. Absorbiendo en refinerías nacionales sólo un porcentaje de petróleo pesado extraído, el resto es vendido directamente en el mercado externo o procesado por altos costos en instalaciones en el exterior. Existe, por tanto, un desfase entre las líneas de extracción y la capacidad de procesamiento de la empresa (IBARRA, 2013).

Frente a las disparidades técnicas, en 2004 se fue delineando entre peritos y políticos la necesidad de mudar el modus operandi de la compañía Petróleos Mexicanos (ROUSSEAU, 2012). Especialistas referían el costo político que lleva hacer una reforma en el tema de petróleo, debido a la importancia dada por la población, y un punto de referencia para la adquisición del estado de bienestar nacional, además de proporcionar recursos (MEIXUEIRO Y BACA, 2013).

Contra todas las anteriores consideraciones, el Gobierno Federal decidió retirar al Estado del control sobre sus recursos energéticos, que se venía consolidando históricamente, a través, de la resistencia al boicot internacional y de la lucha social que llevo a la constitución del Leviatan mexicano, o sea, del Estado como un príncipe investido de recursos que le permitieron algo de soberanía.

La nacionalización del petróleo tiene sus orígenes en 1938, después de la crisis nacional causada por el conflicto entre trabajadores y empresas de petróleo de origen extranjero; después de varias tentativas de mediación, fue decidido expropiar las empresas petroleras y crear una empresa de naturaleza pública (MEIXUEIRO Y BACA, 2013). Durante el tiempo recorrido, la industria petrolífera mexicana creció y se consolidó, hasta transformar nuestro país en uno de los principales productores de hidrocarburos en el mundo (NAVARRO, 2007). Podemos decir, también, que el conflicto entre empresas y gobiernos extranjeros contra el Estado 
mexicano por el control de petróleo, se tornó un símbolo de gran fuerza en el imaginario colectivo que exalta el nacionalismo y la defesa de soberanía.

Más tarde, entre 1946 y 1958, dice González (2013), llama la atención las reformas que permitieron que empresas extranjeras hiciesen trabajos de exploración de nuevos yacimientos. Al final de ese período, las empresas estaban contribuyendo con $2 \%$ de la producción total de los hidrocarburos, más, en otras áreas de la cadena de producción, tales como la prestación de servicios, la participación fue mayor. Cerca del final del período del Presidente Adolfo Ruíz Cortines (1952-1958), propuso varias alteraciones para limitar el crecimiento de la presencia extranjera en el sector o promulgar una ley que reglamentara el Artículo 27 de la Constitución, en el sector de Petróleo.

El mismo artículo afirma que:

Corresponde a la nación la propiedad directa, inalienable e imprescriptible de todos los hidrocarburos que están localizados en el territorio, incluyendo los mantos de la plataforma continental o depósitos, independientemente de su estado físico, incluyendo los estados intermedios y que componen el petróleo mineral bruto, acompañan o provienen de éste(Artículo 27 de la Constitución Mexicana).

Dos años después, el presidente Adolfo López Mateos (1958-1964) consolidó el monopolio estatal iniciado por Lázaro Cárdenas, en 1938. El sector de energía terminó por cerrarse para el capital privado (GONZÁLEZ, 2013).

El artículo 27 de la Constitución fue definido:

[...] El caso del petróleo y los carburos sólidos, líquido e hidrógeno gaseosos, no serán concedidas concesiones y contratos, ni subsistirán los que hayan sido concedidos y que el país llevara la exploración de esos productos en los términos establecidos por la ley de reglamentación respectiva (Artículo 27 de la Constitución Mexicana).

En tanto, en el año 2013 se dejó la ventana abierta para que Pemex realizara con otros individuos o entidades la ejecución de obras y la prestación de servicios que se encuentra en el $6^{\circ}$ artículo de la Ley de Reglamentación del Artículo Constitucional 27 en el sector petrolífero, siendo muy claro que los pagos serán en dinero y no serán concedidos por servicios prestados a los trabajos que son ejecutados, porcentajes en los productos o participación en los resultados de las operaciones (GONZÁLEZ, 2013; LUNA, ET AL. 2019).

Artículos 25, 27 y 28, las mudanzas realizadas (en negrito): 
Artículo 25

\begin{tabular}{|c|c|}
\hline Antes & \\
\hline $\begin{array}{l}\text { Corresponde al Estado la rectoría } \\
\text { del desarrollo nacional para garan- } \\
\text { tizar que éste sea integral y susten- } \\
\text { table, que fortalezca la Soberanía } \\
\text { de la Nación y su régimen demo- } \\
\text { crático y que, mediante la compe- } \\
\text { titividad, el fomento del crecimien- } \\
\text { to económico y el empleo y una } \\
\text { más justa distribución del ingreso } \\
\text { y la riqueza, permita el pleno ejer- } \\
\text { cicio de la libertad y la dignidad de } \\
\text { los individuos, grupos y clases so- } \\
\text { ciales, cuya seguridad protege esta } \\
\text { Constitución. La competitividad se } \\
\text { entenderá como el conjunto de } \\
\text { condiciones necesarias para gene- } \\
\text { rar un mayor crecimiento econó- } \\
\text { mico, promoviendo la inversión y } \\
\text { la generación de empleo. } \\
\ldots \\
\ldots \\
\text { El sector público tendrá a su car- } \\
\text { go, de manera exclusiva, las áreas } \\
\text { estratégicas que se señalan en el } \\
\text { Artículo } 28, \text { párrafo cuarto de la } \\
\text { Constitución, manteniendo siem- } \\
\text { pre el Gobierno Federal la propie- } \\
\text { dad y el control sobre los organis- } \\
\text { mos que en su caso se establezcan. }\end{array}$ & $\begin{array}{l}\text { Corresponde al Estado la rectoría del desarrollo nacional para } \\
\text { garantizar que éste sea integral y sustentable, que fortalezca la } \\
\text { Soberanía de la Nación y su régimen democrático y que, median- } \\
\text { te la competitividad, el fomento del crecimiento económico y } \\
\text { el empleo y una más justa distribución del ingreso y la riqueza, } \\
\text { permita el pleno ejercicio de la libertad y la dignidad de los in- } \\
\text { dividuos, grupos y clases sociales, cuya seguridad protege esta } \\
\text { Constitución. La competitividad se entenderá como el conjunto } \\
\text { de condiciones necesarias para generar un mayor crecimiento } \\
\text { económico, promoviendo la inversión y la generación de empleo. } \\
\text {... } \\
\ldots \\
\text { El sector público tendrá a su cargo, de manera exclusiva, las áre- } \\
\text { as estratégicas que se señalan en el Artículo } 28, \text { párrafo cuarto } \\
\text { de la Constitución, manteniendo siempre el Gobierno Federal } \\
\text { la propiedad y el control sobre los organismos que en su caso } \\
\text { se establezcan. Tratándose de la planeación y el control, del sis- } \\
\text { tema eléctrico nacional y del servicio público de transmisión y } \\
\text { distribución de energía eléctrica, así como de la exploración y } \\
\text { extracción de petróleo y demás hidrocarburos, la Nación llevará } \\
\text { a cabo dichas actividades en términos de lo dispuesto por el pár- } \\
\text { rafo sexto y séptimo del artículo } 27 \text { de esta Constitución. En las } \\
\text { actividades citadas la ley establecerá las normas relativas a la ad- } \\
\text { ministración, organización, funcionamiento, procedimiento de } \\
\text { contratación y demás actos jurídicos que celebren las empresas } \\
\text { productivas del Estado, así como el régimen de remuneraciones } \\
\text { de su personal, para garantizar la eficacia, eficiencia, honestidad, } \\
\text { productividad, transparencia y rendición de cuentas con base en } \\
\text { las mejores prácticas y determinará las demás actividades que } \\
\text { podrán realizar. }\end{array}$ \\
\hline
\end{tabular}

Artículo 27

\begin{tabular}{|l|l|}
\hline Antes & Después \\
\hline Tratándose del petróleo y de los & Tratándose de minerales radioactivos no se otorgarán \\
carburos de hidrógeno sólidos, & concesiones. Corresponde exclusivamente a la Nación la \\
líquidos o gaseosos o de minerales & planeación y el control del sistema eléctrico nacional, así como \\
radioactivos, no se otorgarán & el servicio público de transmisión y distribución de energía \\
concesiones ni contratos, ni & eléctrica; en estas actividades no se otorgarán concesiones, \\
subsidiarán los que en su caso & sin perjuicio de que el Estado pueda celebrar contratos con \\
se hayan otorgado y la Nación & particulares en los términos que establezcan las leyes, mismas \\
llevará a cabo la explotación de & que determinarán la forma en que los particulares podrán \\
esos productos, en los términos & participar en las demás actividades de la industria eléctrica. \\
que señale la Ley Reglamentaria & Tratándose del petróleo y de los hidrocarburos sólidos, líquidos \\
respectiva. Corresponde & o gaseosos, en el subsuelo, la propiedad de la Nación es \\
exclusivamente a la Nación generar, & inalienable e imprescriptibley no se otorgarán concesiones. Con \\
conducir, transformar, distribuir & el propósito de obtener ingresos que contribuyan al desarrollo \\
y abastecer energía eléctrica que & de largo plazo de la Nación, ésta llevaráa cabo las actividades de \\
tenga por objeto la prestación de & exploración y de extracción del petróleo y demás hidrocarburos \\
servicio público. En esta materia & mediante asignaciones a empresas productivas del Estado o a \\
no se otorgarán concesiones a los & través de contratos con éstas o con particulares, en los términos \\
particulares y la Nación aprovechará & de la Ley Reglamentaria. Para cumplir con el objeto de dichas \\
los bienes y recursos naturales que & asignaciones o contratos las empresas productivas del Estado \\
se requieran para dichos fines. & podrán contratar con particulares. En cualquier caso, los \\
$\ldots$ & hidrocarburos en el subsuelo son propiedad de la Nación y así \\
$\ldots$ & deberá afirmarse en las asignaciones o contratos. \\
$\ldots$ & $\ldots$
\end{tabular}


Artículo 28

\begin{tabular}{|c|c|}
\hline Antes & Después \\
\hline $\begin{array}{l}\text { El Estado tendrá un banco central que será } \\
\text { autónomo en el ejercicio de sus funciones y en } \\
\text { su administración. Su objetivo prioritario será } \\
\text { procurar la estabilidad del poder adquisitivo de } \\
\text { la moneda nacional, fortaleciendo con ello la } \\
\text { rectoría del desarrollo nacional que corresponde } \\
\text { al Estado. Ninguna autoridad podrá ordenar al } \\
\text { banco conceder financiamiento. }\end{array}$ & $\begin{array}{l}\text { El Estado contará con un fideicomiso público } \\
\text { denominado Fondo Mexicano del Petróleo para } \\
\text { la Estabilización y el Desarrollo, cuya Institución } \\
\text { Fiduciaria será el banco central y tendrá por objeto, } \\
\text { en los términos que establezca la ley, recibir, } \\
\text { administrar y distribuir los ingresos derivados de las } \\
\text { asignaciones y contratos a que se refiere el párrafo } \\
\text { séptimo del artículo } 27 \text { de esta Constitución, con } \\
\text { excepción de los impuestos. } \\
\ldots \text { El Poder Ejecutivo contará con los órganos } \\
\text { reguladores coordinados en materia } \\
\text { energética, denominados Comisión Nacional de } \\
\text { Hidrocarburos y Comisión Reguladora de Energía, } \\
\text { en los términos que determine la ley. } \\
\ldots \\
\ldots\end{array}$ \\
\hline
\end{tabular}

Del año 1978 al año 2004, Pemex experimentó un período de prosperidad. Después de ese período, hubo un decline en la producción, promovido por el agotamiento de Cantarell, lo mismo que mostró la necesidad de reformar Pemex (MEIXUEIRO Y BACA, 2013).

El expresidente Salinas de Gortari, en su Plan Nacional de Desarrollo, estableció la separación de varias empresas estatales, incluyendo la petroquímica secundaria para atraer la inversión privada nacional y extranjera, creando siete filiales petroquímicas: Cosoleacaque, Tula, Escolín, Camargo, La Cangrejera, Morelos y Pajaritos (Rousseau, 2012; Carreón y Grunstein, 2011). En tanto, en 2004, la Secretaría de Energía se dice sorprendida por los resultados obtenidos de la filial, no fueron los deseados, por causa de la falta de desarrollo en el sector privado. Esa participación supera los cinco mil millones de dólares (IMCO, 2013).

Se establecieron acuerdos internacionales envolviendo el tema de emisión de hidrocarburos nacionales y de participación privada de empresas de otros países en la industria del petróleo como el Acuerdo de Libre Comercio de América del Norte (TLCAN). El tratado no proporciona el acceso a la inversión privada en casi todo el proceso de producción; en tanto, hay una cláusula de desempeño que establece que cada país envuelto en el Tratado debe permitir que sus empresas estatales negocien cláusulas de desempeño en sus contratos de servicio, por lo que Pemex puede negociar contratos de servicios con el sector privado nacional y extranjero. Un instrumento que torno posible la capacidad de inversión a los proyectos denominados de In- 
fraestructura Productiva con Impacto Diferido en el Registro de Gasto, más conocido como Pidiregas. Se muestra, de esa forma, los modelos de participación de las empresas privadas en el sector de los hidrocarburos (IBARRA, 2013; GONZÁLEZ, 2013; 2014).

Durante su mandato, el expresidente Vicente Fox (2000-2006) lanzó la reforma y con una mayor fuerza y radicalidad Felipe Calderón (2006-2012) tomó decisiones con base en un documento elaborado por la Secretaría de Energía y Pemex, llamado Diagnóstico: situación de Pemex, por el cual Pemex demanda ser tratada como una empresa, tanto en su administración, gestión y autonomía interna. La respuesta inmediata de ese presidente fue insertar consejeros técnicos independientes, en vez de trabajadores del gobierno, a través, de concesiones, de ciertas libertades organizacionales y de deuda. Esa acción fue llamada presidencial, pues el nombramiento de directores y la creación de agencias estaban sujetas a la voluntad presidencial. En tanto, se debe considerar la correlación de fuerzas, por cuanto las legislaturas, había más presencia del PRI. (ROUSSEAU, 2012).

Petróleos Mexicanos es la tercera petrolera más rentable en el mundo, teniendo en cuenta el retorno sobre el capital invertido (GONZÁLEZ, 2014; 2013). Pemex vuelca su renta económica para el sector público a través de varios impuestos y tasas, por tanto, si esos fuesen incluidos en el cálculo de su tasa ROIC, la rentabilidad de Petróleos Mexicanos sería cero (GONZÁLEZ, 2014).Las rentas de Pemex son equivalentes a la suma de las cinco mayores empresas que operan en el país: América Móvil, Femsa, Wallmart, Alfa y Cemex (González, 2014).

La reforma también incentiva la participación privada en el sector de energía, en la exploración estratégica y la extracción de petróleo y gas natural. El Centro Nacional de Control de Gas Natural surge como órgano público descentralizado, responsable por la operación del transporte nacional, sistema de gasoductos y almacenamiento de combustible. (GONZÁLEZ, 2013).

\section{Petróleo y desposesión: el poder de cooptación}

El Estado definió las rentas del petróleo para fortalecer el poder del capital. Las políticas adoptadas por los diferentes Estados no han sido las mismas, por ejemplo, Argentina y Bolivia privatizaron, Brasil y Venezuela, abrieron al capital privado algunos segmentos de la industria; México per- 
maneció, hasta el 2013, con el estatuto de empresa pública. Existe la idea de una privatización jurídica diferente de la propiedad pública, mismo cuando fueron mixturados los criterios económicos sobre los políticos en la gestión empresarial (GONZÁLEZ, 2014).

John M. Ackerman (2015) afirma como Meixueiro y Baca (2013) que la mayoría de la población está contra la privatización de la industria petrolera. La prioridad de las empresas no es la exploración directa de petróleo, más el control financiero sobre nuevas reservas, a fin de inflar su listado en la bolsa de valores. No es gratuito, por ejemplo, la quinta regla transitoria de la Reforma Energética, explícitamente que dice: “aunque el petróleo mexicano continúe siendo propiedad de la nación, las empresas privadas son beneficiadas con nuevas licencias, lo que resultará en efectos contables y financieros". Contrato pertinente y beneficios esperados.

Las compañías de petróleo son los principales establecimientos comerciales que procuran el beneficio de sus accionistas, lo que se refleja en el precio de las acciones de corto plazo en la bolsa de valores y la distribución de dividendos a largo plazo. Lo que importa es el posicionamiento estratégico dentro de la industria (RODRÍGUEZ, 2015; ACKERMAN, 2015).

Después de realizar sus nuevos contratos en Wall Street, las compañías mexicanas de petróleo no vacilarán en dirigir su capital fijo a las latitudes más rentables. El caso de Repsol en Argentina es un excelente ejemplo de las contradicciones que muchas veces son generadas en campo. En 2012, Christina Fernandez Kirchner fue tan lejos con el propósito de nacionalizar a la empresa en respuesta a lo que ella consideraba una política de vaciamiento, no hay producción y no hay exploración de las compañías petroleras (ACKERMAN, 2015).

Hay muchas dudas sobre la capacidad del Estado mexicano, y la voluntad del grupo dominante actual, para contener las necesidades de las compañías petroleras tan poderosas como la Exxon-Mobil, Shell y de Chevron. Días después de la promulgación de la reforma de petróleo, el presidente mexicano dio una clara señal de sumisión a esas empresas, curvándose a las presiones de las mayores empresas del país para firmar un decreto que las exenta de una serie de nuevos impuestos aprobadosapenas un par de meses anteriores (ACKERMAN, 2015).

Un escenario posible, dice Ackerman (2015) que, al negarse a recoger los impuestos necesarios, y mucho menos ser capaz de evitar daños graves al 
medio ambiente derivados de la extracción de petróleo, un peligro latente, es cuando las técnicas del fraqueo son usadas ${ }^{1}$.

Además de eso, en México, el Gobierno Federal, el Congreso y la Suprema Corte difícilmente podrían resistir a la presión de las compañías petroleras a tomar medidas semejantes. La impunidad que vienen disfrutado las empresas mineras canadienses en suelo mexicano es apenas una muestra de la ola de destrucción ambiental que podría surgir como resultado de la nueva reforma (Ackerman, 2015).

La reforma energética no pretendió reducir la emisión de gases de efecto invernadero, sino de incentivar la exploración de petróleo y gas. El gas natural encontrado en formaciones geológicas profundas y dispersas. Una vez que esas rocas tienen baja permeabilidad es necesario hidráulicamente fracturar la roca para permitir que el gas suba a la superficie. Son necesarios entre 11,000 y 19,000 litros de agua, mixturados con agentes tóxicos. Para remover el agua contaminada, ella es inyectada a varios kilómetros de profundidad. De acuerdo con el Departamento de Energía de los Estados Unidos, México tiene grandes reservas de gas, especialmente en las partes del norte del país: Coahuila, Chihuahua, Nuevo León, Tamaulipas, precisamente en la región donde hay escasez de agua (SHEINBAUM, 2015).

Claramente, la intención es desvalorizar a Pemex y la Comisión Federal de Electricidad para substituirlos por Chevron, Shell, Halliburtony las empresas corruptas de generación de energía eléctrica y defraudadoras como Enron (ACKERMAN, 2015). Mc Crunmen(2013) afirma, en un artículo publicado por el The Washington Post el 13 de agosto, que las empresas transnacionales incurrieron en prácticas laborales abusivas e ilegales sistemáticamente, como en 1938.

Para promover la Reforma Energética, el gobierno federal llego a anunciar la conclusión del proyecto de la refinería Bicentenario, de manera persuasiva, no informativa, con la intención de ganar el apoyo de la opinión pública y anticipar los argumentos nacionalistas,históricos y sociales de izquierda (MÁRQUEZ, 2015). La pieza central de la reforma fue eliminar al Estado de la

1 En Francia, el Consejo Constitucional apoya recientemente la técnica de prohibición de fracturas. En Estados Unidos, un grupo de ONG ha ganado recientemente un gran ensayo en el ámbito del medio ambiente contra la empresa Shell, planea parar la exploración y extracción de petróleo en el Ártico durante años. En Ecuador, el gobierno alcanzó una histórica victoria al imponer multas a Chevron por su polución ambiental agresiva e irresponsable del país (ACKERMAN, 2015). 
exclusividad de abrir toda la cadena de producción nacional e internacional de petróleo y gas para el capital privado, induciendo esquemas de petróleo y gas semejante al de un contrato de concesión (SHEINBAUM, 2015).

La reforma energética fue una parte integral del vasto esquema de dislocamiento del complejo petroeléctrico articulado con la Secretaría de Finanzas, a través de empresas de consultoría Cambridge Energy Associates; McKinsey, Booz Allen Hamilton y fundaciones como Heritage, cuyos estudios, tres décadas atrás, Petróleo y prosperidade: la reforma del monopolio de petróleo de México son un programa de ajuste estructural para la desnacionalización de todas las actividades de upstream, exploración y producción bien profunda, refinado, petroquímica, distribución, comercialización, para las empresas ExxonMobil, Chevron/Texaco, Conoco/ Phillips, BP-Amoco e Shell (SAXE-FERNÁNDEZ, 2015; SACHER, 2015).

Saxe-Fernández (2015) sintetiza el análisis realizado por Fernando Siqueira, de la Asociación de Ingenieros de Petrobras, que observa la mudanza en la ley para Petrobras, es ruin para Brasil. Este país tenía el control del petróleo y paso a tener el $10 \%$. Una vez abierto no tiene más control. La abertura tiende a crecer cada vez más, poderosas empresas presionan, de modo que la presión es difícil de controlar, cuya abertura es gradual, no existiendo control sobre ella.

Además, Saxe-Fernández (2015) presenta un análisis de Ildo Luís Sauer, ex-director de Petrobras (2003-2007): así que llegaron los leones, ellos entran al sistema y tendrán la fuerza para participar con mucho más poder que el sistema político y económico, dominar los medios de comunicación e infiltrarse en partidos políticos, a través de lobistas que están en el Congreso y en los salones de gobierno.

El exdirector de Petrobras acusó de espionaje a la Agencia de Seguridad Nacional (NSA) contra la presidente Dilma Rousseff y de Petrobras, una operación que él dice consiste en robar secretos comerciales, identificar los hilos flacos en la cadena de comando para saber dónde penetrar, con quién negociar (SAXE-FERNÁNDEZ, 2015).

El discurso de privatizar a Pemex no es descartado fuera del país. SaxeFernández (2015b) indica que un integrante de la Secretaría de Energía anunció en el Wall Street Journal (18/06/13) que gustaría de tornar claramente en la Constitución mexicana cómo las empresas privadas pueden participar. 
Las empresas quieren pagar los impuestos mínimos posibles y aprovechar la estabilidad fiscal, si los sistemas fiscales favorecen que sean dispensados de la obligación de abastecer el mercado interno, o por lo menos serán autorizados a vender a precio de mercado. Libre convertibilidad de moneda y libre repatriamento de capitales son dos de las condiciones irreductibles. Evaden cláusulas con implicaciones financieras significativas en temas que no son estrictamente petróleo, tales como el desenvolvimiento social, el cuidado ambiental y preservación de vida silvestre. No aceptan que la disputa sea realizada en diferentes tribunales internacionales (RODRÍGUEZ, 2015).

Galeano (1971) dice en su libro clásico Las venas abiertas de América Latina:

Standard Oil y Shell remueven reyes y presidentes, financian conspiraciones y golpes de Estado, tienen generales, ministros e incontables espías. El Petróleo tiene impregnado presidentes y dictadores, enfatiza las deformaciones estructurales de la sociedad. Son las empresas las que deciden el mapa del mundo (p. 255).

VictorRodriguez (2015) preguntó, ante lo que afirma Eduardo Galeano, en el siglo XX (1971):

¿Las transnacionales fueron regeneradas después que perdieran sus concesiones en el Medio Oriente, Venezuela y en otros lugares? ¿Renunciaran a sus prácticas pasadas? ¿Ya se tornaron dignas y honradas? Su nombre aparece en muchas de las guerras, golpes, desastres ecológicos de los últimos 30 años en Angola, Yemen, Sudán, Somalia, Indonesia, Los Balcanes, el Golfo Pérsico, Afganistán, Colombia, Perú, Ecuador, Timor Occidental, Zaire (p. 246).

La ganancia por el petróleo y el gas natural representa la causa y el efecto de confrontación entre grupos, pueblos y países. Donde hay conflicto geopolítico, dicen Harvey (2004) y Rodríguez (2015), están las compañías petrolíferas. En África, los golpes frecuentes tienen olor al diablo negro. Las amenazas de guerra en Oriente Medio también huelen a petróleo. En Asia Central se creó una disputa feroz por el control de depósitos y rutas de evacuación (RODRÍGUEZ, 2015).

En Estados Unidos se consolida una visión energética continental. Fundamentalmente, la visión de energía del hemisferio occidental 
es profundamente compleja e interrelacionada, con oportunidades espectaculares para generar puestos de trabajo en Estados Unidos, a sus intereses comerciales, su desarrollo económico y seguridad energética ligada a las perspectivas políticas de Canadá, México, Venezuela, Caribe y demás. Los mercados de energía del mundo son transformados, reflejando la propia revolución energética, Estados Unidos, dice, tiene mucho que compartir y mucho que ganar por hacer parte de esta visión.Esto es especialmente cierto en el hemisferio occidental. Desde la construcción de la seguridad energética de los Estados Unidos y en la formación de mercados de gas natural, para formar el camino para las negociaciones de transformación e innovación, Estados Unidos debe liderar para compartir las mejores prácticas y lecciones aprendidas, apoyando la transparencia y un piso liso, y dar a nuestras empresas e innovaciones acceso a los mercados de energía del mañana. Todas estas actividades son fundamentales para alcanzar nuestra propia seguridad energética y para lograr un mayor desarrollo económico, el acceso a la energía y la estabilidad para un futuro más fuerte, seguro y próspero para las Américas (PASCUAL, 2013).

Hay documentos muy importantes en los cuales el Senado de los Estados Unidos afirma, claramente, que precisa de México para continuar el envío 1,500,000 barriles de petróleo por día. Entre la corrupción de la élite mexicana y la presión de Estados Unidos empujó la reforma (BARLETT, 2015; MONREAL, 2014; GONZÁLEZ, 2014).

Los procesos de flexibilización económica no proporcionaron mejores productos y servicios a precios competitivos a nivel internacional. Estos procesos han herido a nuestra sociedad y contribuido a la formación de monopolios y oligopolios, que no sólo producen ineficiencias económicas y falta de competencia, sino que acaban acelerando la concentración de la riqueza y del rendimiento nacional (IBARRA, 2013).

Los verdaderos vencedores de la reforma energética son los bancos extranjeros que financiaron transnacionales y recibieron intereses de las rentas del petróleo; empresas extranjeras que irán a apropiarse una parte de las recetas del petróleo y de los mercados energéticos en México, o que irá a generar lucros para sus accionistas, venidos de recetas del petróleo; empresas de máquinas y tecnología, que reciben pagamentos más elevados de los pagos en otros países, los cuales seránefectuados con parte de las recetas del petróleo; gobiernos y ciudadanos extranjeros reciben impuestos 
pagados por las empresas que operan en México; exfuncionarios mexicanos y un pequeño grupo de empresarios mexicanos se tornaran consultores, consejeros y accionistas de empresas nacionales y extranjeras, se beneficiaran de la reforma (CÁRDENAS, 2015).

\section{Desvalorización para la acumulación}

Desde la compra de las tierras a los campesinos de Atitalaquia y Tula, Hidalgo, la región se convirtió en blanco del capital financiero. El inicio de la especulación en Hidalgo, gradualmente, tiende a las orgías especulativas en las que el Estado es socio del capital.

Regionalmente, el engaño de la refinería Bicentenario permitió reforzar la política de posicionamiento. El proyecto involucró al menos US\$ 11.000.000.000 de dólares en licitaciones internacionales y desposesión de tierras agrícolas campesinas.

El padrón de acumulación muestra una ventaja de diferenciación geográfica de competencia local sobre circunstancias específicas. La formulación de los proyectos se encuadra en un padrón de eficacia de los programas locales para la acumulación en diferentes escalas económicas y políticas (PECK, 2010; SACHER, 2015).

La acumulación incesante del capital es permanentemente posicionada a través de las reformas. El capital no es un producto físico, pero una relación social, que se basa en la destrucción de la propiedad privada ganada por sí mismo; en otras palabras, la "expropiación del trabajador” (HARVEY, 1990 p. 416).

Además de eso, las revoluciones en tecnología, medios de comunicación y transporte, la centralización y descentralización de capital (incluyendo el grado de integración vertical), en los arreglos de crédito e infraestructura física y social, afectan materialmente el equilibrio de las fuerzas en acción. Eso empuja al capital en fases que profundizan las configuraciones espaciales de las fuerzas productivas y las relaciones sociales (HARVEY, 1990, p. 421).

Con el capital fijo y servicios inmobiliarios, el capital está preso en un valor de uso específico, mientras que los otros factores son inalterados, el grado de fijación depende de la duración. El capital fijo empatado involucra el imperativo de la acumulación e impone otro imperativo: "Así, cuanto mayor sea la escala en que se desarrolla el capital fijo, más se convierte en la continuidad del proceso de producción y el constante flujo de producci- 
ón una condición externamente atractiva para el modo de producción basado en capital” (HARVEY, 2014 p. 266, MARSTON, 2010, HIRSCH, 2011; INCLÁN et al. 2012).

El capitalismo es necesariamente caracterizado por un esfuerzo perpetuo para superar todos los obstáculos espaciales "aniquilando el espacio a través del tiempo". (HARVEY, 2014 p. 348). "El dinero es apenas un medio de movimiento, asume un poder independiente y externo en cuanto al cambio" (HARVEY, 1990 p. 249). Todo poder es social, tan determinado, limitado. No funciona, sin constituciones e instituciones, establecidas o mejoradas. Es el arte de usar las instituciones, manipular a las personas con las instituciones y manipular las propias instituciones; en suma, el poder político es el arte de gobernar. El Estado junto con el capital privado formó una asociación para gobernar sobre los territorios y sus recursos, incorporando la fuerza de trabajo existente dentro de las fronteras nacionales (HIRSCH, 2011; LACOSTE, 1977; LÓPEZ Y RAMÍREZ, 2010).

El crédito se utiliza para acelerar las inversiones, la producción y el consumo, simultáneamente. Como se evidenció con la deuda adquirida por los dos gobiernos, Hidalgo y Guanajuato, para la adquisición de terrenos para la refinería, estimuló los beneficios inmobiliarios de empresas como la ICA, Isolux y otras. El inmenso poder potencial reside en el sistema de crédito. La localización adecuada del crédito puede garantizar un equilibrio cuantitativo entre estos dos sectores, la producción y el consumo (HARVEY, 1990: 289).

La refinería Bicentenario fue un proyecto para superar la crisis a través de la acumulación por desposesión. Esa propuesta permitió la valorización del capital financiero para inversiones en capital productivo con base en la política de posicionamiento (TORTOSA, 2010; SACHER, 2015).

Las condiciones de instalación del proyecto de la refinería Bicentenario llevaron a una cuestión de conflicto territorial, perpetuando la crisis en el ámbito de la regulación, energía, social y territorial. Después de la compra de la tierra, conflictos familiares vinieron para incentivar asesinatos entre los miembros de las familias y asaltos a las personas.

Los ejidatarios de Atitalaquia y Tula vendieron cerca de 700 hectáreas, de una tierra que, en el pasado, había contribuido al cultivo de alfalfa, maíz, frijoles y chile. Se puede afirmar que la valorización por especulación fue concomitante con la devaluación del suelo rural y la caída de la productividad de las actividades agrícolas. Ver Foto 1. 
Foto 1. La región y las mudanzas

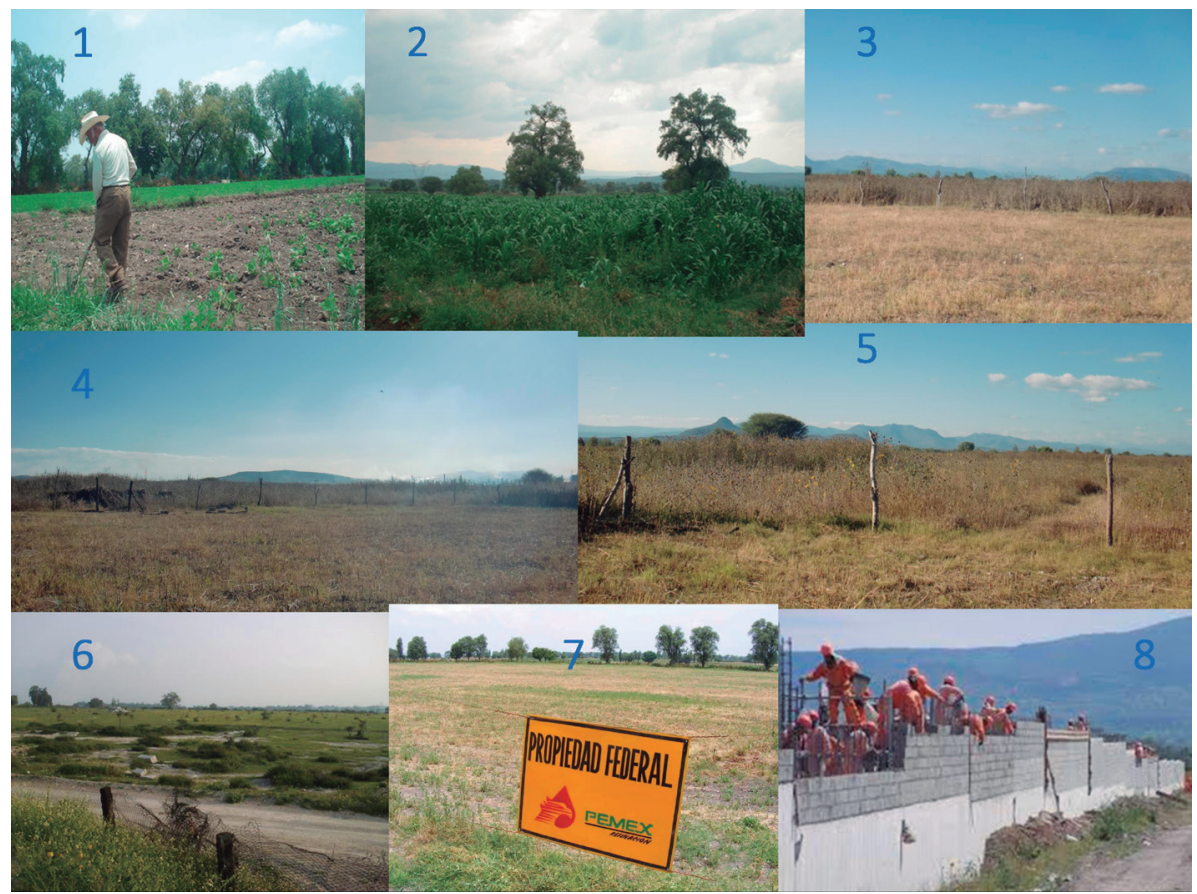

Elaboración propia, 2009-2015. 1) Trabajando la tierra, 2) Cultivo de tierra, 3) Tierra sin uso, 4), 5), 6), 7), 8) Obras del proyecto.

La región Atitalaquia-Tula, Hidalgo es la síntesis de múltiples determinaciones históricas y espaciales (LUNA, 2016A; 2016B; 2016C; 2016d). Para observar estas determinaciones tenemos que conectar la escala regional, con otras escalas de influencia.

Las reformas en México, propuestas por el poder ejecutivo en 2013, formularon programas de asistencia social, activación de las condiciones de normalización y de socialización entre desempleados y pobres en el mercado de trabajo.

\section{Conclusiones}

Las reformas desencadenaron un proceso de especulación vinculado con todos los factores técnico-económicos y socioculturales. La delimitación que se realizó de la refinería no es puramente geográfica, como el espacio fue entendido, en forma de contenedor, sino para tener en cuenta aspectos 
económicos, sociales, étnicos y políticos. De la misma forma, el territorio donde se encuentra no es homogéneo, muy al contrario, existen diferencias en las distintas áreas que lo componen. Las formas sociales tienden a reducir los hombres a números, pero también transforma los recursos naturales, como el petróleo en el demonio o dioses. La vida distorsionada, con toda certeza, emerge de las cosas, transformando los productos sociales en seres animados, el petróleo en México es ese terrible Diablo Negro, el "Dios de los señores de la tierra", un ser animado del que se dice devora a los hombres que le dan vida. La demanda incesante del petróleo pasa por la estructura axiomática que define la cosificación. La racionalidad del capital sucumbió a su irracionalidad autoinducida y de las mercancías como el petróleo que cobra vida con sentido humano.

La política de posicionamiento tiene una estrategia de crecimiento hacia fuera, hizo de la manufactura y los recursos naturales el principal sector de la economía. Trabajo barato y tributación privilegiada.

La economía nacional depende fuertemente de los ingresos del petróleo. El artículo 27 de la Constitución da un papel estratégico a la energía: reclama para la nación la propiedad de los recursos del subsuelo y entrega a Pemex el control de toda la cadena de producción, incluso antes de la reforma energética, logró abastecer durante 30 años el mercado nacional como una energía de bajo costo, promoviendo así el desarrollo industrial en algunos sectores clave de la economía: la agricultura con los fertilizantes, así como el transporte y ramales industriales: cemento, vidrio, industria de hierro y acero, etc.

La reforma energética fue una parte incondicional del vasto esquema de desplazamiento del complejo petroeléctrico articulado, un programa de ajuste estructural para la desnacionalización de todas las actividades de upstream, exploración y producción, así como aguas abajo, refinación, petroquímica, distribución, comercialización, para las empresas ExxonMobil, Chevron/Texaco,Conoco/ Phillips, BP-Amoco y Shell.

Los verdaderos vencedores de la reforma energética son los bancos, capitales financieros extranjeros.Quienes financiarán trasnacionales y recibirán intereses de los ingresos del petróleo; empresas extranjeras que se apropiarán una parte de los ingresos del petróleo y de los mercados energéticos en México. Empresas de maquinaria y tecnología, que reciben pagos más elevados que los pagados en otros países, los cuales se efectuarán con parte de los ingresos del petróleo; ex funcionarios mexicanos y un pequeño grupo de 
empresarios mexicanos se convirtieron en consultores, consejeros y accionistas de empresas nacionales y extranjeras.

Así, el Estado actúa sobre los territorios para crear un modelo fijo de acumulación. Con la reforma energética participará el capital extranjero en la exploración de hidrocarburos en áreas rurales y costeras, que transforma áreas agrícolas en terrenos para uso de todo el proceso de producción de energía a partir de recursos naturales, desestimulando el campo para la producción agrícola.

\section{Referencias}

BARLETT, Manuel (2015), “Reforma energética”. In: CÁRDENAS, Jaime (coord.). Reforma Energética. Análisis y consecuencias. México: UNAM.

CÁRDENAS, Jaime (2015), "La reforma constitucional en materia de energía”. In: . Reforma Energética. Análisis y consecuencias. México: UNAM.

CARREÓN, Victor y GRUNSTEIN, Miriam (2011), "Pemex: ¿la no empresa de todos los mexicanos? Por qué Pemex no es una verdadera empresa pública y por qué debe serlo". Revista Legislativa de Estudios Sociales y de Opinión Pública. Vol. 4, n. 8, julio-diciembre.

GALEANO, Eduardo (1971), Las venas abiertas de América Latina. México: Siglo XXI.

GONZÁLEZ, José (2013), Refinerías en México. Retos y posturas para una revisión en el ámbito legislativo. México: Centro de Estudios Sociales y de Opinión Pública.

GONZÁLEZ, José (2014), Reforma Energética, refinerías y opinión pública. México: Centro de Estudios Sociales y de Opinión Pública.

GRUNSTEIN, Miriam (2015), "Reforma petrolera: pasos y tropiezos del proceso de México”. In: CÁRDENAS, Jaime (coord.). Reforma Energética. Análisis y consecuencias. México: UNAM.

HARVEY, David (1990), Los límites del capitalismo y la teoría marxista. México: Fondo de Cultura Económica.

HARVEY, David (2003), The New Imperialism. Oxford, New York.

HARVEY, David (2004), La condición de la posmodernidad. Investigación sobre los orígenes del cambio cultural. Buenos Aires: Amorrortu.

HARVEY, David (2014), Espacios del capital. Hacia una geografía crítica. México: Akal. 
HIRSCH, Joachim; KANNANKULAM, John (2011), “The Spaces of Capital: The Political Form of Capitalism and the Internationalization of the State". Antipode. 43, 1, 12-37, Jan.

HIRSCH, Joachim (2001), El Estado Nacional de Competencia. Estado democracia y política en el capitalismo global. México: Universidad Autónoma Metropolitana-Xochimilco.

IBARRA, David (2013), “Crisis y reformismo en México”. Configuraciones, 35. México. p. 17.

IMCO (2013), Nos cambiaron el mapa. México ante la revolución energética del siglo XXI. México: Instituto Mexicano para la Competitividad.

INCLÁN, Daniel; MILLÁN, Márgara; LINSALATA, Lucia (2012). "Apuesta por el valor de uso: aproximación a la arquitectónica del pensamiento de Bolívar Echeverría”. Íconos. Revista de Ciencias Sociales n. 42, mayo, pp. 19-32.

LACOSTE, Yves (1977), La geografia: un arma para la guerra. Barcelona: Editorial Anagrama.

LEFEBVRE, Henry (2006), La presencia y la ausência. Contribución a la teoría de las representaciones. México: Fondo de Cultura Económica.

LEFEBVRE, Henry (1991), The Production of Space. New York: Blackwell Publishing.

LÓPEZ, Liliana; RAMÍREZ, Blanca (2010). Pensar el espacio: región, paisaje, territorio y lugar en las ciencias sociales. Mimeo.

LUNA, Luis; DE LA ROSA, Javier; RAMÍREZ, Judith (2017), “El poniente de la Ciudad de México: el secreto público”. Revista Vozes dos Vales: Publicações Acadêmicas, 12(VI), pp.1-27.

LUNA, Luis (2014), "La estrategia de posicionamiento del Estado Nacional de Competencia: una visión de la condición rural en México”. Vozes dos Vales, 06, pp. 1-17,

LUNA, Luis (2016a), "Escalas y determinaciones en la reforma a la propiedad de los energéticos: México”. Revista electrónica de estudios latino-americanos, v. 14, pp. 41-55.

LUNA, Luis (2016b), "A Refinaria Bicentenario no estado de Hidalgo, México: espaço representado e desvalorizado”, GEOGRAFIA (Londrina), 2, 25, pp. 40-59.

LUNA, Luis (2016c), "Representação da refinaria Bicentenário: Hidalgo, México”. Estudos Geográficos, 14, pp. 62-78.

LUNA, Luis (2016d), "História de uma região para o refinação: AtitalaquiaTula, México”. Revista Hominum, 5, pp. 239-258. 
LUNA, Luis (2017a), "Representação e produção do espaço: duas conceituações analisadas por Henri Lefebvre”. Revista Diaphonía, 1, 3, pp. 21-32.

LUNA, Luis (2017b), "Subsunção dos atores sociais pela Refinaria Bicentenario: Hidalgo, Mexico”. Aceno, 7(4), pp. 315-332.

LUNA, Luis (2017c), Transiciones en el campo mexicano. Género, identidad y trabajo. México: Universidad Autónoma Metropolitana-Unidad Lerma, p. 245.

LUNA, Luis; ANDRADE, María; MORALES, Jesús (2019), Despojo de la refinería Bicentenario. México: Instituto Politécnico Nacional.

McCRUNMEN, Stephanie (2013), "Mexican oil workers fear Pemex proposal”. The Washigton Post, 13 de Ago.

MARQUÉZ, Daniel (2015), “Modelos histórico-jurídicos de contratación en petróleos mexicanos”. CÁRDENAS, Jaime (Coord.). Reforma Energética. Análisis y consecuencias. México: UNAM. 2015.

MARSTON, Sally (2000), “The social construction of scale”. Progress in Hunan Geography. 24(2), pp. 219-225.

MEIXUEIRO, Gustavo; BACA, Arón (2013), La reforma energética en la opinión pública. México: Centro de Estudios Sociales y de Opinión Pública, p. 29.

MONREAL, Ricardo (2014), Privatización del petróleo. El robo del siglo. México: D3 Ediciones S.A. de C.V.

PASCUAL, Carlos (2013), Writen Testimony of Special Envoy and Cordinator for International Energy Affairs. Subcommittee on the Western Hemisphere United States House of Representatives, Energy and the Western Hemisphere.

PECK, Jamie (2010), "Economías políticas de escala: políticas rápidas, relaciones interescalares y workfare neoliberal”. In: FERNÁNDEZ, Ramiro; BRANDAO, Carlos (coord.). Escalas y políticas del desarrollo regional. Argentina: Miño y Davila-Universidad de Litoral.

RODRÍGUEZ, Victor (2015), "Los riesgos de los contratos de riesgo".

CÁRDENAS, Jaime (coord.). Reforma Energética. Análisis y consecuencias. México: UNAM.

ROUSSEAU, Isabel (2012), "Pemex y la política petrolera: los retos hacia el futuro”. In: MÉNDEZ, José Luis. Los grandes problemas de México. Políticas Públicas. México: El Colegio de México.

SACHER, William (2015), "Megaminería y desposesión en el Sur: un análisis comparativo”. Íconos. Revista de Ciencias Sociales núm. 51, Quito, Enero. pp. 99-116. 
SAXE-FERNÁNDEZ, John (2015), La compraventa de México. Una interpretación histórica y estratégica de las relaciones México-Estados Unidos. México: UNAM y Centro de Investigaciones Interdisciplinarias en Ciencias y Humanidades.

SAXE-FERNÁNDEZ, John (2015b). "Flexibilización constitucional y reingreso a México de las petroleras nacionalizadas por Lázaro Cárdenas”. CÁRDENAS, Jaime (coord.). Reforma Energética. Análisis y consecuencias. México: UNAM.

SHEINBAUN, Claudia (2015), "La Reforma Energética en el contexto internacional”. CÁRDENAS, Jaime (Coord.). Reforma Energética. Análisis y consecuencias. México: UNAM.

TAUSSIG, Michael (1993), El diablo y el fetichismo de la mercancía en Sudamérica. México: Nueva Imagen.

TAUSSIG, Michael (2015), La magia del Estado. México: Siglo XXI.

TORTOSA, José. (2010), "Las nuevas violencias en la crisis global. Íconos. Revista de ciencias Sociales, n. 36, enero, pp. 41-52.

\section{(cc) $\mathrm{EY}$}

Licenciado sob uma Licença Creative Commons Attribution 3.0 